\title{
Comunidade, senso comum e igreja invisível em Kant
}

\author{
Margit Ruffing
}

Professora na Johannes Gutenberg-Universität em Mainz

Tradução: Monique Hulshof 

Um dos conceitos kantianos interpretados frequentemente e de bom grado é o de "ânimo" (Gemüt). Mais do que outros conceitos usados por Kant para designar a constituição (Verfasstheit) espiritual dos seres humanos - como consciência ou razão -, este conceito parece-nos mostrar que a investigação filosófica pela totalidade da consciência (assim como a busca da consciência pela totalidade) não é apenas uma "ideia da razão", mas pertence à condição humana.

Particularmente no contexto da Antropologia do ponto de vista pragmático Kant utiliza o termo "ânimo" (Gemüt) como sinônimo de "consciência" (Bewusstsein). Com base na concepção kantiana de consciência humana, gostaria de examinar, a seguir, alguns aspectos referentes às condições do "espírito" (Geist) humano, cujas características são a cooperação (Zusammenwirken) - ou sinergia, em sua expressão moderna - das faculdades de conhecimento (a saber, sensibilidade, entendimento e razão) e dos sentimentos mais especificamente ligados à racionalidade ${ }^{1}$.

Para isso escolhi o conceito de "comunidade" (Gemeinschaft), tomado em um sentido amplo que nos permite considerá-lo não apenas como categoria lógica, mas antes como indicador de uma consciência moderna, cuja subjetividade não conduz nem a um solipsismo teórico nem a um individualismo filosófico-moral. A problemática a que minhas reflexões se referem é a da dificuldade de se pensar o caráter genérico (gattungshaft) e supraindividual da razão - não apenas considerada como atributo dos exemplares da humanidade, enquanto espécie dos seres capazes de consciência, mas também considerada como expressão da personalidade (Menschsein), da humanidade, que se realiza apenas em existências individuais. Diferentemente da "intersubjetividade", a "razão

1 Em outro lugar já tratei desta temática: cf. M. RUFFING. Die Bedeutung des Gefühls in Kants Religionsphilosophie. In: J. ALBERTZ (Ed.). Aufklärung, Vernunft, Religion - Kant und Feuerbach. Berlim: Schriftenreihe der Freien Akademie, 2005, v. 25; e também idem. Sentiment moral et sentiments religieux chez Kant. Conferência realizada no II. Trilateralen Kant-Kolloquiums Lissabon 2009 (no prelo). 
genérica" (gattungshafte Vernunft) representa uma concepção filosófica que não parte do princípio da individualidade para explicar como uma "comunidade de seres humanos" torna-se possível e realizável. Trata-se, antes, de uma concepção que procura esclarecer os fundamentos apriorísticos ou "quase" apriorísticos da comunicação e do entendimento mútuo dos indivíduos enquanto representantes da humanidade.

Com o intuito de circunscrever um pouco a temática, serão antecipadas algumas reflexões gerais sobre a preocupação de Kant em desenvolver - com a filosofia transcendental crítica -, com base na unidade da razão orientada teórica e praticamente, uma autocompreensão dos seres humanos como "seres racionais sensíveis" capazes de moralidade.

A cooperação (Zusammenwirken) das faculdades do conhecimento - sensibilidade, entendimento e razão - pode ser considerada como característica da consciência humana. Esta é compreendida, desde a famosa revolução copernicana de Kant, como uma consciência subjetiva, originada da autocerteza (Selbstgewissheit), que busca o conhecimento do objeto. Entretanto, a certeza da sensibilidade vivida individualmente e o saber produzido pela razão genérica (gattungshafte Vernunft), que pretende validade universal, são diferentes quanto ao modo, mesmo que possam ser semelhantes quanto à intensidade. Antes de tudo, constitui-se para a certeza da experiência (Erfahrungsgewissheit), que a si mesma se basta, o problema da publicidade e da comunicabilidade de seu conhecimento.

Considero que, em seu pensamento, Kant constantemente se esforça - mesmo de maneira implícita - para satisfazer a necessidade metafísica da razão, sem perder de vista, porém, a problemática das ideias da razão que, mesmo se afastando da certeza da experiência (Erfahrungsgewissheit), possuem ainda assim realidade para os seres humanos. Por mais provisório que seja o único conhecimento metafísico positivo, que é o do "limite" - como se apresenta ao final dos Prolegômenos -, não se abandona com isso 
a pretensão de se constituir uma metafísica completamente crítica, isto é, não dogmática. A convicção, constantemente defendida por Kant, de que todo o saber do homem (do "eu"), do mundo e de Deus tem de ser unido em um só sistema filosófico representa esse problema; o Opus postumum documenta o quanto a busca por um sistema completo- não coroada pelo sucesso - orientou seu pensamento.

Um saber sistemático sobre a personalidade (Menschsein) enquanto Eu no Mundo perante Deus, único saber que pode satisfazer a razão, pressupõe, a meu ver, um tipo de "integração filosófica" das faculdades da consciência. A Crítica da razão pura teve explicitamente a tarefa de explicar como podemos representá-las. A reflexão filosófica sobre a cooperação (Zusammenwirken), porém, é levada adiante, com maior ou menor profundidade, passando pela Crítica do juízo até a Religião nos limites da simples razão.

Em vez do conceito muito discutido de "limite", gostaria de enfatizar uma "concordância" (Übereinstimmung) a ser ainda definida de maneira mais exata, que deve argumentar a favor da tese de que o ser racional não se realiza com base na consciência do indivíduo. Três conceitos centrais, provenientes da teoria do conhecimento, da filosofia da religião e da Crítica do juízo - "Comunidade", "senso comum" e "igreja invisível" -, documentam o fato de que (e a maneira pela qual) Kant resolve a dificuldade de um sistema de conhecimentos positivos, do qual a filosofia, segundo ele, deve certamente tratar com a mais cuidadosa determinação de limites. Dito de outro modo, documentam a maneira pela qual Kant, renunciando aos juízos sintéticos a priori, assume um ponto de vista antropológico nas considerações teóricas da consciência ${ }^{2}$.

2 Cf. I. KANT. Prolegomena zu einer jeden künftigen Metaphysik, die als Wissenschaft wird auftreten können, AA o4, $\$ 57$, "Von der Grenzbestimmung der reinen Vernunft". 
A primeira parte (I) reflete inicialmente sobre a utilização e a função do conceito de "comunidade" (Gemeinschaft) no contexto da lógica (com referência à Crítica da razão pura). Na segunda parte (II) interpreto algumas observações de Kant, presentes na Crítica do juízo, sobre o "senso comum" (Gemeinsinn), que, sem estar baseado na experiência, deve possibilitar juízos - por exemplo, o juízo de gosto - no domínio do apreensível (Erfahrbaren). Esses juízos remetem a um sentimento em comunidade e nesta medida podem conduzir a um "assentimento" (Beistimmung) ou uma "concordância" (Übereinstimmung). Diferentemente da dimensão lógica do conceito, a "comunidade" da concordância (Gemeinschaft der Übereinstimmung) mostra que, e como, um entendimento mútuo pode ser pensado com base em uma autocompreensão (Selbstverständnis) individual. A última parte (III) ocupa-se, por fim, do ideal da comunidade efetiva dos humanos enquanto seres racionais, cujo "ser comum" (gemeines Wesen) qua razão é um ser moral, que se designa como "igreja invisível”, na medida em que é reconhecido como algo que está submetido à legislação divina.

\section{I. "Comunidade" (Gemeinschaft)}

Consideremos inicialmente a categoria de "comunidade" na medida em que se refere a todo o pensamento e ao conhecimento teórico. De acordo com Kant, o pensamento é dependente de seu acompanhamento pelo "eu"; a produção de representações depende de uma instância designada por ele como "unidade sintética da apercepção". Essa disposição - o "eu penso" que acompanha a representação - não pode ser posta em questão, nem se pode prosseguir sua justificação. Da mesma maneira, a representação de algo depende de um pensamento sobre uma comunidade, um "junto" (Zusammen) ou uma unidade do diferente (Verschiedenartigen), cujo questionamento não pode ser levado adiante. O próprio Kant formula o problema no contexto da Crítica da 
razão pura como fundamental para o conhecimento teórico: algo substancial, que é distinto do "eu”, não pode ser compreendido sem a categoria de comunidade em geral. É, todavia, possível pensar que mais substâncias existam e que estejam em conexão umas com as outras: que elas se influenciem mutuamente e, como diz Kant,

que da existência de uma possa seguir-se de maneira recíproca algo na existência de outra (como efeito), e, portanto, que, pelo fato de haver algo na primeira deve haver também nas outras algo, que não pode ser entendido unicamente a partir da existência dessas³.

É exatamente isso que "comunidade" designa no contexto lógico: o saber sobre a existência e a influência mútua das substâncias - a do Eu e a do diverso - diferentes e cognoscíveis enquanto diferentes, ou seja, distinguíveis. Sob esta condição, de que as substâncias isoladas existam, permanece, entretanto, incompreensível o modo com que elas possam saber algo umas das outras. Por este motivo Leibniz, segundo Kant, ainda recorre a Deus para explicar a "mediação" das substâncias e o conceito lógico de "comunidade"4. Para Kant, em contrapartida, a "realidade objetiva" desse conceito não pode ser nem compreendida pela razão pura, nem explicada por uma divindade - que não é, ela mesma, nem compreensível, nem explicável. Kant oferece uma outra explicação para o fato de que mesmo assim podemos representar a possibilidade da comunidade com relação a substâncias isoladas; fazemos isso com ajuda do espaço, na intuição externa, pois este “contém já a priori relações externas formais, que são a condição

3 I. KANT. Kritik der reinen Vernunft (B), AA o3: 201; idem. Crítica da razão pura. Trad. de M. dos Santos, A. F. Morujão. Lisboa: Fundação Calouste Gulbenkian, 2o10, B293/294.

4 "Eis por que Leibniz, ao atribuir uma comunidade às substâncias do mundo, somente tais como o entendimento por si só as concebe, precisou da mediação de uma divindade para a explicar; porque, a partir da sua simples existência, essa comunidade lhe parecia justificadamente inconcebível" (id., ibid.). 
da possibilidade das relações reais (de ação e reação e, portanto, da comunidade)"5. O que é que existe no particular nunca é compreendido quanto à essência, mas, na medida em que o espaço é a representação a priori de relações externas, pode-se pensar que existem diferentes seres "lado a lado", os quais podem sempre produzir efeitos um sobre o outro. Nossa consciência dispõe, assim, da categoria formal da comunidade e é, por isso, capaz de conhecer a existência - não a essência - de substâncias diferentes. É capaz de distinguir entre o "eu" das representações de "algo", sem poder determinar continuamente o "que", isto é, sem conceber e compreender a essência dos objetos representados. Do mesmo modo, nossa existência humana, quanto à essência, permanece incompreensível pela categoria de comunidade, na medida em que essa existência não coincide com as relações formais, como o estar "lado a lado" no espaço.

Nessa situação de ignorância e incerteza, Kant remete-nos a nós mesmos, e não - como o faz Leibniz - a um ser divino que garante a identidade dos seres existentes a despeito de suas diferenças, permitindo que no conhecimento seja atribuída "comunidade” às substâncias do mundo. Para Kant a consciência humana é suficiente para compreender a "comunidade" como estrutura existencial: ela realiza-se no e pelo indivíduo, cuja sensibilidade permite a percepção da própria existência e da de outro, na medida em que o faz sob as condições de sua forma a priori do espaço. A consciência que conceitualiza (o entendimento) forma essas percepções ou sensações em conformidade com o modo pelo qual a intuição "funciona", isto é, ele pensa algo que se encontra em relações externas com outra coisa - pensamento que tem de ser acompanhado pelo "eu penso" enquanto representação de algo que constitui. A comunidade de seres extensos e pensantes 
encontra-se, portanto, já no indivíduo humano, capaz de consciência, enquanto ser caracterizado pela “[...] comunidade da alma com o corpo"6.

Na medida em que é desde sempre cognoscente - "eu penso" -, o sujeito, segundo Kant, contém em si, nas formas da intuição pura da sensibilidade e nas categorias do entendimento, o fundamento da comunidade. O pensamento a priori da comunidade é uma condição de possibilidade da experiência e, por isso, a base para o nosso conhecimento do mundo.

Esse significado da comunidade como fundamento a priori de nosso conhecimento pela experiência é complementado por um outro aspecto: a possibilidade de "concordância" (Übereinstimmung) quanto ao juízo de experiência, dada já estruturalmente no conhecimento ou consciência humana. A possibilidade de "concordância" (Übereinstimmung) contém e condiciona também a de assentimento (Beistimmung) quanto ao juízo de gosto estético. Com isso, a categoria formal de "comunidade" torna-se a base para uma consciência humana genérica (gattungshaften): ao caráter formal da categoria teórica de comunidade, acrescenta-se então o conteúdo da sensação. Aquilo que é apreendido sensivelmente entra no juízo de gosto como sentimento, efetuando prazer ou desprazer. O juízo de gosto exerce um papel particular nessa conexão. Neste juízo a "comunidade" exprime-se como uma "concordância" com o juízo de experiência, ou como seu "assen-

6 A comunidade é reconhecida como e pela intuição de fenômenos, formada e ligada pela sensibilidade corporal, fenômenos que se reportam uns aos outros pelas relações externas, mas que em si mesmos, isto é, quanto à essência, não são compreensíveis, assim como não é compreensível a própria intuição que condiciona o pensamento da comunidade. Kant utiliza o conceito de "comunidade" no contexto das explicações sobre o idealismo transcendental na primeira edição da Crítica da razão pura ou da refutação do idealismo da segunda edição: quanto à comunidade dos seres extensos e pensantes, trata-se afinal de "saber como é possível, num sujeito pensante em geral, uma intuição externa, a saber, a intuição do espaço (do que o preenche, a figura e o movimento). Mas quanto a esta questão não é possível a homem algum encontrar uma resposta [...]" (idem. Kritik der reinen..., op. cit., AA 04: 245; idem. Crítica da razão..., op. cit., А393). 
timento", tornando possível uma certa generalidade ou mesmo universalidade no plano subjetivo.

\section{II. "Senso comum" (Gemeinsinn)}

Desde a revolução copernicana de Kant, o ponto de partida para o conhecimento é o indivíduo: a facticidade existencial de sua vivência sensível, ou seja, da experiência, é acompanhada de uma certeza subjetiva, ligada ao "justamente aqui" - a um lugar exatamente determinado - e ao "justamente agora" - a um tempo exatamente determinado - do objeto, que é designada como "conhecimento"7. O caráter singular, múltiplo, heterônomo do objeto, apreendido pelo sujeito e compreendido como determinável no tempo e no espaço, poderia ser, sob este aspecto, uma característica do próprio objeto. Teoricamente, à certeza da vivência sensível corresponderia a determinação constante e completa do objeto - por assim dizer, o conhecimento "objetivo". Entretanto, a crítica da razão feita por Kant deixa claro que nossa representação, nosso pensamento, sendo determinado por suas formas subjetivas, não pode compreender o objeto tal como é em si: a "coisa em si" permanece necessariamente desconhecida. Em outras palavras: o juízo de experiência - juízo que se refere ao objeto de nossa experiência, dizendo algo sobre ele - não pode obter sua validade objetiva universal e necessária com base no conhecimento do objeto (como "saber objetivo"), mas apenas da conformidade às leis (Gesetzmäßigkeit) do juízo, isto é, com base no sujeito. $\mathrm{O}$ entendimento subjetivo garante a objetividade do conhecimento compreendendo o objeto mediante a regulação categorial.

Em contrapartida, no juízo de percepção subjetivo, que se ori-

7 Cf. o início da introdução da Crítica da razão pura $\left(\mathrm{B}_{1}\right)$ : "Não resta dúvida de que todo o nosso conhecimento começa pela experiência; pois, que outra coisa poderia despertar e pôr em ação a nossa faculdade de conhecer senão os objetos que afetam os sentidos [...]” (I. KANT, Crítica da razão..., op. cit.). 
gina sem a compreensão intelectual, a sensação exprime-se como a primeira verbalização, de certa maneira, "não trabalhada", do acontecimento perceptivo, que é anterior ao conceito, ao pensamento. A meu ver, é por esta razão que o sujeito é frequentemente identificado com o indivíduo: o conhecimento parece estar, com efeito, inseparavelmente ligado à vivência perceptiva individual. Mas como passar do juízo de percepção subjetivo ao juízo que corresponda ao objeto, a um juízo que reivindique necessidade e validade universal, sem possuir um caráter a priori? Esta questão é, primeiramente, de importância epistemológica, porque se trata de pressupor - e de demonstrar - uma faculdade de conhecimento ou de consciência que permite afirmações sobre a determinação dos objetos no mundo, em função da experiência baseada na percepção, ou seja, que possibilita o saber científico. Kant tratou desta problemática na Crítica da razão pura e nos Prolegômenos.

O significado antropológico da questão sobre a cooperação (Zusammenwirken) das faculdades da consciência mostra-se sobretudo na maneira pela qual esta é tratada na Crítica do juízo. Ali Kant explica de que modo um juízo subjetivo (que se refere materialmente a um sentimento que acompanha a percepção) é possível enquanto juízo de caráter universal e necessário. Trata-se dos juízos de gosto. Proferir esses juízos, diz Kant, exprime uma “Anmaßung", que pode ser traduzida por "pretensão" - aspecto muito provavelmente proposto por Kant -, mas que também remete, em sua origem germânica, a "Maß”" (medida) ou "angemessen" (adequado ou congruente). Por isso o fato de a "Anmaßung" do juízo de gosto possuir um caráter apriorístico não é ou não pode ser apenas uma pretensão da consciência - no sentido que ele faz uma promessa que nunca se materializa. Nós consideramos, antes, adequado à nossa consciência humana proferir juízos estéticos ou juízos de gosto. Além disso, é um fato que nós o fazemos - como é um fato (empírico) de que existe a beleza no mundo dos fenômenos, algo que não se explica nem pela legislação da natureza, nem pela da liberdade. Proferir juízos de gosto requer, 
segundo Kant, a pressuposição de algum caráter legislativo ou ao menos regulador: "a norma indeterminada do senso comum".

A explicação epistemológica do senso comum - "o efeito do livre jogo de nossos poderes de conhecimento"9 enquanto condição de possibilidade do juízo de gosto $^{10}$ - introduz uma outra faculdade da consciência: dado que nem os conceitos nem a experiência são capazes de justificar o juízo de gosto, além das faculdades capazes de conhecimento - sensibilidade, entendimento e razão -, é preciso invocar o sentimento para justificá-lo. Com isso, Kant enfatiza que não se trata de um "sentimento pessoal e privado", mas de um "sentimento comunitário" (gemeinschaftliches Gefühl l". A dimensão antropológica das proposições manifesta-se já nas expressões linguísticas: o sujeito gramatical utilizado por Kant neste contexto é "wir" (nós), "man"12 ou até mesmo "jedermann" (todos ou qualquer um). Certamente não se trata de um fenômeno empírico. Então como explicar o caráter comunitário de um sentimento não empírico? Kant propõe a seguinte explicação: o que caracteriza o senso comum não é nem um sentido, isto é, uma capacidade de sensação ligada a um órgão, nem o sentimento de gosto, mas consiste no fato de constatar que "o juízo de gosto atribui a todos assentimento", que "se angaria o assentimento de todos os outros"13. É, portanto, a busca pela concordância (Übereinstimmung), pelo assentimento (Beistimmung), que indica o senso comum: "angaria-se o assentimento de todos os outros, porque se tem para isso um fundamento (Grund) que é comum a todos"14. Este "fundamento que é comum a todos" possui uma

8 Cf. I. KANT. Kritik der Urteilskraft, \22, AA 05: 239; idem. Crítica do juízo. Trad. de R. R. Torres Filho. São Paulo: Abril, 1974.

9 Cf. idem. Kritik der Urteilskraft, final do $\$ 20$.

10 Cf. id., ibid., $\iint 20$ e 22, AA 05: 239.

11 Cf. id., ibid. Prefiro designar "gemeinschaftliches Gefühl" como um sentimento de comunidade ou um sentimento comunitário, em vez de sentimento comum (N. da A.). 12 Pronome indefinido que pode ser traduzido por "as pessoas" (N. da T.).

13 Cf. id., ibid., $\$ 19$.

14 Id., ibid. 
ambivalência bela e relevante ao tema. Por um lado, pode ser interpretado como a base ou fundamento sentimental, comum a todos os homens e sobre o qual o juízo de gosto se funda. Por outro lado, a palavra "Grund" (fundamento) pode significar a razão pela qual buscamos o acordo com os outros, o motivo ou a causa pela qual "se angaria o assentimento de todos", pois o juízo de gosto exprime o querer entrar em acordo um com o outro, o interesse em comunicar suas próprias sensações e sentimentos aos outros. Aqui encontramos, por assim dizer, a base teórica do interesse humano pelos juízos estéticos ou da convicção da "Anmaßung" no sentido mencionado de congruência à humanidade.

As explicações apresentadas por Kant de que no juízo estético a "finalidade subjetiva" é o conteúdo que queremos comunicar a todos e de que o belo é pensado como algo que tem uma "relação necessária com a satisfação (Wohlgefallen)", parecem um pouco duras. Mas isso ocorre devido à lógica da explicação racional, pois Kant não trata da experiência do juízo de concordância (übereinstimmenden Urteils), mas de seu significado exemplar. A necessidade da relação do belo (do objeto) com a satisfação (enquanto sensação do sujeito) não é uma necessidade teórica, compreensível $a$ priori, nem uma necessidade prática, proveniente de uma lei da razão: "Mas, como necessidade que é pensada em um juízo estético, ela só pode ser denominada exemplar, isto é, uma necessidade da concordância de todos com um juízo que é considerado como exemplo de uma regra universal que não se pode fornecer"15.

Essa posição relativiza o aspecto epistemológico das reflexões de Kant sobre o senso comum na medida em que o juízo é apenas "exemplar", quase secundário (nebensächlich), visto ser considerado como exemplo. Como exemplo de quê? Exemplo de uma "regra universal que não se pode fornecer". A "regra" é a exigência mínima para a demanda por necessidade e, ao mesmo 
tempo, sua garantia. Mas não se fornece nada além da indicação "universal". Por esta razão, precisamos considerar o senso comum como componente antropológico do sistema kantiano, sem deixar de pressupô-lo teoricamente como condição de possibilidade do juízo de gosto, mas sempre o pressupondo praticamente, segundo Kant, na medida em que todos os seres humanos acreditam-se capazes de fazer juízos estéticos e em que eles também o fazem.

Gostaria de concluir minhas considerações sobre o senso comum com uma citação das Reflexões sobre antropologia:

do interesse no gosto - do senso comum - da comunicabilidade das sensações (Mittheilbarkeit der Empfindungen). Humanitas. [...] Nos dois juízos estéticos (quanto ao belo e ao sublime da natureza) a finalidade subjetiva é a matéria (Inhalt) que se quer comunicar universalmente (allgemein). Nos dois, a intuição determina o juízo. A imaginação contém a síntese comunicável pelo entendimento e pela razão.

No juízo de gosto há algo de lógico, na medida em que exige um assentimento (Beystimmung) [...]. Mas difere do [juízo) lógico na medida em que esta validade universal não repousa sobre o acordo (Zusammenstimmung) do modo de representar com o objeto, mas sobre a relação das faculdades de representar (que pertencem ao conhecimento) no sujeito, a saber, em cada sujeito. $[\ldots]^{16}$.

Kant fala aqui de um juízo determinado pela intuição. Além

16 I. KANT. Reflexionen zur Anthropologie, AA 15: 437. "Vom Interesse am Geschmak - dem Gemeinsinn - Mittheilbarkeit der Empfindungen. Humanitas. [...] In beyden asthetischen Urtheilen [Schönes und Erhabenes der Natur] ist subiective Zwekmaßigkeit der Inhalt, den man allgemein mittheilen will. In beyden bestimt Anschauung das Urtheil. Einbildungskraft enthalt die Synthesis, die für Verstand und Vernunft allgemein Mittheilbar ist. Geschmacksurtheil hat darinn etwas Logisches, daß es allgemeine Beystimmung Gebietet, [...] Darinn aber unterscheidet es sich doch vom Logischen, daß diese Allgemeingültigkeit sich nicht auf der Zusammenstimmung der Vorstellungsart mit dem Objecte, sondern mit dem Verhältnis der Vorstellungsvermögen (die zum Erkentnis gehören) im Subjecte, und zwar jedem Subjecte gründet. [...]". Kant termina de maneira lacônica com uma observação entre parênteses: (g a universalidade da satisfação, certamente não por conceitos, mas na intuição é o difícil) [( $\mathrm{g}$ Die Allgemeingültigkeit des Wohlgefallens, und doch nicht durch Begriffe, sondern in der Anschauung, ist das Schwierige.)] (id., ibid., AA 15: 438). 
disso, admite que a síntese entre o que é sentido subjetivamente e o que é comunicado a todos universalmente é feita pela imaginação. A necessidade expressa no juízo é de caráter exemplar. A universalidade exigida é e permanece fundada subjetivamente e só se torna universal mediante a concordância (Übereinstimmung) de muitos/todos os indivíduos humanos ${ }^{17}$. Trata-se, por assim dizer, de uma universalidade sumariamente acreditada, mas pressuposta como necessariamente possível. É importante notar que Kant acrescenta "Humanitas" - em relevo - à enumeração "do interesse no gosto, do senso comum, da comunicabilidade das sensações". Em termos mais fortes: após a "revolução copernicana", uma concepção filosófica do homem não como individual, mas como ser racional representante do gênero humano, não é viável sem se pressupor o senso comum, que, por sua vez, não é possível sem se pensar a comunidade como categoria da compreensão recíproca dos seres diferentes (não somente como categoria intelectual). A comunidade compreendida como "concordância" (Übereinstimmung) entre os seres humanos deve poder ser finalmente pensada como ideia prática: a ideia da comunidade dos seres racionais no mundo, o corpo ético e a igreja invisível.

\section{A igreja invisível (unsichtbare Kirche)}

Kant apresenta o significado da "concordância" (Übereinstimmung) enquanto ideia prática no ideal da "igreja invisível", entendida como "ideia da união de todos os homens corretos (Rechtschaffenen) sob o governo divino imediato, mas moral, do mundo, tal como serve de arquétipo às que devem ser fundadas por homens"18. Enquanto ideia, a igreja invisível não é um objeto da experiência, diferentemente da igreja visível, que é definida 
como "a união efetiva dos homens em um todo que concorda com aquele ideal”’19. Para que os homens se reúnam, a fim de estabelecer uma "comunidade ética sob uma legislação divina moral", ou seja, uma igreja, eles têm de poder reconhecer a "ideia racional” desta comunidade, assim como sua própria obrigação em relação à legislação da comunidade ética. Os homens são capazes de fazer isso mediante a razão, pois podem reconhecer as "leis naturais" de uma religião - que correspondem às ideias prático-morais da razão e, finalmente, à própria lei, o imperativo categórico. A igreja enquanto comunidade ética depende, portanto, de que os homens reconheçam a concordância da lei moral com a legislação divina; mas, acrescenta Kant, "pela religião racional de cada um não existe ainda nenhuma igreja enquanto união universal"2o. Para que se origine uma "universalidade coletiva, i.e., uma união dos crentes numa igreja (visível) segundo princípios de uma religião racional pura" ${ }^{21}$, é necessário uma "unanimidade universal" - uma forma de concordância (Übereinstimmung) que exprime a ideia prática da "religião natural enquanto moral".

Da mesma maneira que o senso comum é a condição de possibilidade da concordância dos seres humanos no juízo de gosto, o conceito racional prático da religião natural contém o fundamento cognitivo para a concordância entre a lei da razão e a legislação divina. Neste contexto, concordância significa para Kant "unanimidade universal", que é a condição da "verdadeira" igreja que possui "qualificação para a universalidade" e a "validade para cada um" "22. Que essa "unanimidade" não possa ser alcançada e tenha de ser vivida em religiões efetivas, com leis estatutárias ou regulações (Verordnungen), isto é, deva poder ser vivenciada enquanto igreja visível, é o tema dominante da filosofia da religião

19 I. KANT. Die Religion innerhalb der Grenzen der bloßen Vernunft, AA o6: 101; idem. A religião nos limites da simples razão. Trad. de A. Morão. Lisboa: Edições 70, p. 107. 20 Idem. Die Religion innerhalb..., op. cit., AA o6: 157; idem. A religião..., op. cit., p. 159. 21 Idem. AA o6: 158; idem. Religião, p. 160. 22 Id., ibid. 
kantiana. Com ela Kant procura determinar a relação da igreja invisível enquanto ideal e "arquétipo" com a igreja visível a ser estabelecida, considerando "a associação permanente [dos homens] em uma igreja universal visível" "um dever particular dos homens" e "um meio para o fim supremo deles"23.

Efetiva ou empiricamente, decerto se mostrariam diferenças, mas não oposições inconciliáveis entre a forma no mundo e a forma religiosa da comunidade ética, se o "trabalho" na comunidade visível for compreendido segundo o ideal e o arquétipo da igreja invisível enquanto um dever particular dos homens - na medida em que ambas correspondem ao fim supremo da humanidade e exigem o aperfeiçoamento da espécie "seres humanos racionais". A submissão voluntária à lei, isto é, a intensidade da obrigação com relação ao dever, é decisiva. Apenas quando se pode considerar os deveres como mandamentos divinos, é que se garante que todos os membros da comunidade reconheçam, como senhor, o legislador que conhece e quer o bem de maneira puramente racional, e não por inclinações sensíveis ou interesses egoístas. Nisso consiste, segundo Kant, a religiosidade dos homens.

Em resumo, pode-se dizer que, de acordo com Kant, somente o saber sistemático da existência humana como aquela de um eu no mundo perante Deus pode satisfazer a razão. Partindo das três ideias transcendentais (da alma, do mundo e de Deus), a necessidade metafísica da razão é uma "disposição natural" (Naturanlage)24, e também faz parte da natureza da razão o esforço para alcançar a integralidade, ou seja, a ideia de totalidade. O fim último do sistema é, portanto, uma compreensão de si mesmo e do mundo, abrangente e fundada na ciência. A cientificidade baseia-se na validade apriorística do conhecimento, sendo a aprioridade a garantia de certeza. O verdadeiro conheci-

23 Id., ibid.

${ }_{2}$ Cf. I. KANT. Prolegomena..., op. cit., AA o4, início do \$6o. 
mento exige validade necessária e universal, e, além disso, tem de ser comunicável aos outros. Essas condições são, segundo Kant, cumpridas somente pelo conhecimento do entendimento, que torna concebível e compreensível em um juízo de experiência a sensação formada de maneira espaçotemporal pela intuição. As características da existência humana podem ser por princípio compreendidas, na medida em que se exprimem em juízos de experiência. Em contrapartida, aquilo que se afasta desta certeza de conhecimento, mas completa a compreensão da existência humana, é o pensamento que transcende a experiência e busca a totalidade, atribuído por Kant à razão. Em minhas reflexões sobre o conceito de "comunidade" e sua significação, procurei mostrar que, sob o ponto de vista do conhecimento teórico, trata-se de uma categoria ancorada no pensamento, cujo "uso" evoca uma certeza imediata do saber, que se encontra apenas na experiência. Se o "eu penso" (Ich denke) é compreendido como algo formal acompanhando a representação, a "comunidade" - formal quanto a seu caráter categorial - poderia ser entendida como um complemento material com respeito a este "eu", enquanto a condição a priori da possibilidade da experiência de uma vida racional: "eu, ser racional, penso" 25 . Com essas formulações, não diríamos nada mais que isto: o acordo da consciência pode ser pensado. Também não diríamos nada menos que o seguinte: é legítimo supor que os seres racionais - a saber, o eu e os outros - estejam ligados enquanto membros do gênero humano. Esta suposição é a condição de possibilidade das ideias práticas, isto é, da ideia da humanidade em geral.

A possibilidade da obrigação moral, que se vincula ao dever,

25 "Ich Vernunftwesen denke." Cf. I. KANT. Metaphysik der Sitten, AA o6: 451: “a razão legisladora [...], a qual abarca na sua ideia de humanidade em geral a espécie inteira (logo, também a mim), me inclui igualmente a mim, segundo o princípio da igualdade, como legislador universal, e ainda todos os outros juntamente comigo, no dever de benevolência recíproca" (idem. Metafísica dos costumes. Princípios metafísicos da doutrina da virtude. Trad. de A. Morão. Lisboa: Edições 70, p. 96-7). 
é ao mesmo tempo a condição para a comunidade dos homens, no plano político ligado ao ideal da "comunidade jurídica" na sociedade civil ética, sob a legislação moral divina da comunidade ética, a igreja invisível. Essa comunidade, de acordo com Kant, é aquela, na qual a espécie humana não é pensada como soma de indivíduos, mas enquanto qualidade do ser humano (Menschsein).

\section{Bibliografia}

KANT, I. Crítica do juízo. Trad. de R. R. Torres Filho. São Paulo: Abril, 1974 (Col. Os Pensadores).

. Crítica da razão pura. Trad. de M. dos Santos, A. F. Morujão. Lisboa: Fundação Calouste Gulbenkian, 2010.

. A religião nos limites da simples razão. Trad. de A. Morão. Lisboa: Edições 70.

- Metafísica dos costumes. Princípios metafísicos da doutrina da virtude. Trad. de A. Morão. Lisboa: Edições 70.

RUFFING, M. Die Bedeutung des Gefühls in Kants Religionsphilosophie. In: ALBERTZ, J. (Ed.). Aufklärung, Vernunft, Religion - Kant und Feuerbach. Berlim: Schriftenreihe der Freien Akademie, 2005, v. 25.

Sentiment moral et sentiments religieux chez Kant. Conferência realizada no II. Trilateralen Kant-Kolloquiums Lisabon 2009 (no prelo). 
